\title{
Effect of Cocaine on Dopamine Transporter Receptors Depends on Routes of Chronic Cocaine Administration
}

\author{
Ana Hitri, Ph.D., Karley Y. Little, M.D., and Everett H. Ellinwood, Jr., M.D.
}

Investigation of residual behavioral states produced by withdrawal from different routes of cocaine administration indicates that depending on the mode of intake, chronic cocaine produces either tolerance or sensitization to subsequent challenge doses of cocaine. We studied the effect of routes of cocaine administration on the dopamine transporter receptors (DATR), the presumed neuronal mediator of cocaine reward, using the diphenyl substituted piperazine derivative, $\left[{ }^{3} H\right] G B R 12935$ and the cocaine analogue $\left[{ }^{3} \mathrm{H}\right]$ WIN 35,428 . Alzet osmotic mini-pumps filled with either cocaine $(100 \mathrm{mg} / \mathrm{ml})$ or saline were surgically implanted on rats into a subcutaneous pocket at the dorsal midline, continuously infusing cocaine at the rate of $40 \mathrm{mg} /$ $\mathrm{kg} /$ day. The pumps were removed 14 days later, and the rats were killed 7 days after the removal of pumps. For the intermittent administration, two groups of rats were injected daily either with $40 \mathrm{mg} / \mathrm{kg}$ of cocaine or saline for
14 days. Rats were killed 7 days following the last injection. Continuous infusion of cocaine did not alter the $\left[{ }^{3} \mathrm{H}\right] G B R$ 12935 dopamine transporter (DAT) binding either in the caudate nucleus or in the prefrontal cortex, but it enhanced the density of $\left[{ }^{3} H\right]$ WIN 35,428-labeled DAT receptor sites in the caudate putamen. In contrast, intermittent administration of cocaine resulted in a selective alteration of $\left.{ }^{3} H\right] G B R 12935$ binding in the prefrontal cortex but not in the caudate; the cocaine-injected rats had a $48 \%$ decrease in $\left[{ }^{3} H\right] G B R 12935, \mathrm{~B}_{\max }(\mathrm{p}<.05)$, without changing the $K_{D}$. The contrast between the lack of effect of cocaine on [ $\left.{ }^{3} H\right] G B R$ 12935-DATR and the increased binding of $\left[{ }^{3}\right.$ H]WIN 35,428-DATR highlights the differential sensitivities of the two binding sites to the continuous presence of cocaine. [Neuropsychopharmacology 14:205210, 1996]

ables to the complex behavioral effects associated with the use of cocaine (Broderick 1992; King et al. 1992a; Johanson 1984; Lau et al. 1991; Post and Contel 1983). Animals studied with different histories of cocaine treatment show different behavioral responses to cocaine (Falk et al. 1990; Lau et al. 1991; Reith et al. 1987). Depending on the mode of administration, chronic cocaine produces either tolerance (continuous dosing) (King et al. 1992; Post et al. 1981) or supersensitivity (intermittent dosing) (King et al. 1992a; Lau et al. 1991; Post and Contel 1983; Stripling and Ellinwood 1976) to subsequent challenge doses of cocaine.

The underlying mechanisms of cocaine reinforcement and stereotyped behaviors are believed to be related to the effect of cocaine on dopamine transport- 
ers (DAT) (Ritz et al. 1987). Acutely, cocaine inhibits DAT and prevents the normal reuptake removal of dopamine (DA) from the synapse. Depending on the routes of administration, chronic cocaine administration is associated with both increased (intermittent dosing) and decreased DA efflux (continuous dosing) from the caudate slices (King et al. 1992b). Moreover, withdrawal from repeated administration of cocaine is associated with a reduced clearance rate of DA, indicating significant inhibition of DAT (Cass et al. 1993).

The effects of chronic cocaine exposure on the DAT are complex, with different responses appearing (1) at successive times after the last intake of cocaine (Allard et al. 1990; Hitri and Wyatt 1993; Pilotte et al. 1994; Wilson et al. 1994; Yi and Johnson 1990); (2) with the pattern/dose of cocaine administered (Hitri and Wyatt 1993; Wilson et al. 1994; Yi and Johnson 1990); (3) the anatomical region studied (Hitri and Wyatt 1993; Hitri et al. 1994a; Wilson et al. 1994); and (4) with the radioligand used in the DATR binding studies (Hitri and Wyatt 1993; Kula and Baldessarini 1991; Little et al. 1993; Madras et al. 1989; Wilson et al. 1994).

Cessation of cocaine use in humans results in abstinence symptoms with distinct phases of crash, withdrawal, and extinction. These phases are defined by the appearance of specific symptoms at specific times after the last intake of cocaine (Gawin and Ellinwood 1988; Gawin and Kleber 1986). Human postmortem studies indicate that there are fewer [ $\left.{ }^{3} \mathrm{H}\right] \mathrm{GBR}$ 12935-labeled DAT sites in the prefrontal cortex (Hitri et al. 1994b) and fewer $\left[{ }^{3} \mathrm{H}\right]$ mazindol-labeled DATR sites in caudate nucleus (Hurd and Herkenham 1993) but more $\left[{ }^{3} \mathrm{H}\right]$ WIN 35,428-labeled DATR in the caudate nucleus of cocaine using individuals (Little et al. 1993).

The present study of $\left[{ }^{3} \mathrm{H}\right] \mathrm{GBR} 12935$ and $\left[{ }^{3} \mathrm{H}\right]$ WIN 35,428 binding is part of a series of experiments designed to examine the residual behavior states and their biochemical correlates produced by withdrawal from different modes of chronic cocaine administration and withdrawal times (Stripling and Ellinwood 1976; King et al. 1993; Zhang et al. 1992).

\section{METHODS}

\section{Animals}

Male Sprague-Dawley rats initially weighing 100 to $125 \mathrm{~g}$ were acclimated to the vivarium 1 week prior to treatment. They were housed in pairs in plastic cages with continuous access to food and water. At the end of the study the rats were weighing 275 to $375 \mathrm{~g}$.

\section{Treatments}

Alzet osmotic mini-pumps were filled with 2-ml 100 $\mathrm{mg} / \mathrm{ml}$ cocaine $\mathrm{HCl}$ or saline $(0.9 \%)$ and surgically implanted into a subcutaneous pocket at the dorsal mid- line continuously infusing cocaine through a $(3-\mathrm{cm})$ dialysis tubing at the rate of $40 \mathrm{mg} / \mathrm{kg}$ (Joyner 1993). The pumps were removed surgically 14 days later. Intermittent injection was done by injecting a group of rats subcutaneously once daily with $40 \mathrm{mg} / \mathrm{kg}$ of cocaine and an other group subcontinuously with saline for 14 days (in all previous studies injection and infusion saline animals did not differ).

\section{Brain Dissection}

The prefrontal cortex was dissected from semi-frozen brains by a coronal cut extending to $11,460 \mu$ and by a horizontal cut at the level of rhinal sulcus. The caudate putamen was taken from the coronal sections at the level extending from 9,410 $\mu$ to $7,910 \mu$ (Konig and Klippel 1963).

\section{Tissue Preparation}

The prefrontal cortices were individually homogenized in 30 volumes per weight of ice-cold $50 \mathrm{mM}$ Tris- $\mathrm{HCl}$ buffer containing $5 \mathrm{mM} \mathrm{KCl}$ with $24 \mathrm{mM} \mathrm{NaCl}$, pH 7.9, while the corpus striatum was homogenized in 100 volumes of $50 \mathrm{mM}$ Tris- $\mathrm{HCl}$ with $120 \mathrm{mM} \mathrm{NaCl}$ and $5 \mathrm{mM}$ $\mathrm{KCl}, \mathrm{pH} 7.9$ at $4^{\circ} \mathrm{C}$, with a Brinkman Pt-10 Polytron at setting 6 , for 10 seconds, and centrifuged at $50,000 / \mathrm{g}$ for 10 minutes. The pellet was resuspended in 30 volumes of the same buffer by a Polytron and recentrifuged at $50,000 / \mathrm{g}$ for 10 minutes. The washing was repeated twice, and the final pellet was resuspended in $25 \mathrm{vol}-$ umes for the prefrontal cortex and 100 volumes of assay buffer for the caudate putamen.

\section{[ ${ }^{3} \mathrm{H}$ ]GBR 12935 Binding Assay}

$\left[{ }^{3} \mathrm{H}\right]$ GBR 12935 binding reaction was carried out in the caudate putamen according to the method of Andersen (1987) and in the prefrontal cortex according to the method of Hitri et al. (1991). In the saturation experiments increasing concentrations of $\left[{ }^{3} \mathrm{H}\right]$ GBR 12935 (1$30 \mathrm{nM}$ ) were incubated with aliquots of homogenate corresponding to $4 \mathrm{mg}$ of tissue per assay tube. Nonspecific binding was defined as excess over blanks that contained 0.1 $\mu$ M GBR-12909 (Hitri et al. 1991; Isenwasser and Cox 1990; Yi and Johnson 1990). The incubation was carried out in a final volume of $1 \mathrm{ml}$ at $4^{\circ} \mathrm{C}$ for 60 minutes, and the binding reaction was stopped by rapid ultrafiltration over Whatman GF/B filters. The filters were rinsed twice with $5 \mathrm{ml}$ of ice-cold assay buffer, and the retained radioactivity was measured by conventional scintillation counting.

\section{Data Analysis and Statistics}

The equilibrium binding constants were determined by Scatchard analysis. The raw data expressed as disinte- 
grations per minute (DPM) were subjected to equilibrium binding data analysis (EBDA), using the collection of radioligand binding analysis programs (McPherson 1985). The program provided a mean and the standard error (SEM) for replicate determinations at each point. For each point the program calculated the amount of bound (total, specific) and unbound (free) ligand concentration. The initial estimates of the dissociation constant $\left(K_{D}\right)$ and maximum number of binding sites $\left(B_{\max }\right)$ were obtained from Scatchard plots using EBDA, and for the final estimate of the constants the Ligand program was used.

The binding constants were analyzed with respect to the treatment regimens by one-way analysis of variance (ANOVA). The specific treatment differences were evaluated by the post hoc Tukey's protected $t$-test. All statistical analyses were carried out using the GBSTAT professional statistics and graphics program, version 3.0 (Freedman 1991).

\section{Autoradiographic Assay of $\left[{ }^{3} \mathrm{H}\right]$ WIN 35,428 Binding}

Because of the possibility that $\left[{ }^{3} \mathrm{H}\right]$ WIN 35,428 binding sites were differently regulated from $\left[{ }^{3} \mathrm{H}\right] \mathrm{GBR} 12935$ sites, $\left[{ }^{3} \mathrm{H}\right]$ WIN 35,428 binding was also assessed in the striatum. These experiments were performed autoradiographically to provide increased anatomical detail. Only specimens from the continuously treated animals were available at the time of this study. The autoradiographic studies were carried out according to the method of Little et al. (1993). Briefly, studies were performed using $10-\mu-\mathrm{m}$-thick sections, cryostat-cut at $-20^{\circ} \mathrm{C}$ (Zeiss Micron automated cryostat) and thawmounted on chrome alum/gelatin-coated slides. Incubations were performed with $5 \mathrm{nM}\left[{ }^{3} \mathrm{H}\right] \mathrm{WIN} 35,428$ in $50 \mathrm{mM}$ Tris with $120 \mathrm{mM} \mathrm{NaCl}, \mathrm{pH}$ 7.4. Nonspecific binding for $\left[{ }^{3} \mathrm{H}\right]$ WIN 35,428 was determined in sections exposed to $30 \mu \mathrm{M}(-)$ cocaine. After incubation, slides were washed in succeeding 1-, 10-, and 10-minute washes with ice-cold assay buffer. A 2-minute wash was then done in deionized water. Slides were apposed to Amersham $\left[{ }^{3} \mathrm{H}\right]$-sensitive Hyperfilm for 12 weeks. Amersham $\left[{ }^{3} \mathrm{H}\right]$ standards were co-exposed in each cassette. Film was developed in Kodak D-19 developer for 2 minutes. Optical densities were determined using a MCID image analysis system. The caudate putamen was quantitated in its entirety. Striatal autoradiographic experiments were expressed in $\mathrm{nCi} / \mathrm{mg}$ relative to the standard used.

\section{RESULTS}

Figure 1A illustrates the comparison of $\left[{ }^{3} \mathrm{H}\right] \mathrm{GBR} 12935$ binding constants in the striatum following 1 week of withdrawal from these different chronic treatments. No

\section{$\left[{ }^{3} \mathrm{H}\right]$ GBR 12935}
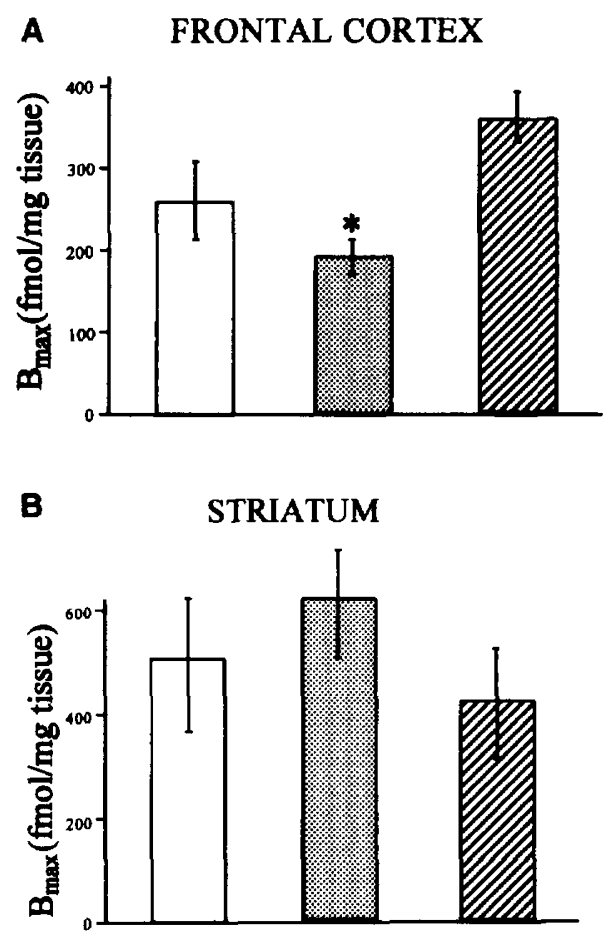

Figure 1. (A) Comparison of $\left[{ }^{3} \mathrm{H}\right] \mathrm{GBR} 12935$ binding site density $\left(B_{\max }\right)$ in the frontal cortex following 1 week of withdrawal from either continuous cocaine administration via mini-pump or intermittent cocaine, or saline, administration via daily injections. $B_{\max }$ was obtained by Scatchard analysis as described in Methods. Significant group differences are indicated by one-way ANOVA $[F(2,15)=5.8, p=.014]$ with a post hoc $t$-test indicating a $48 \%$ reduction in cocaine-injected relative to saline-injected rats $(t=3.4, p=.01)$. The affinity constants $\left(K_{D}\right)$ were not significantly different. (B) Comparison of $\left[{ }^{3} \mathrm{H}\right]$ GBR 12935 binding constants in the striatum following 1 week of withdrawal from these different chronic treatments. No significant group differences were detected for either $B_{\max }$ or $K_{D}$ by a one-way ANOVA [F(2, $15)=.245, p=.79$ and $F(2,15)=0.134, p=.876]$, respectively ( $\square$ saline, 图 cocaine injection, $\square$ cocaine infusion).

significant group differences were detected for either $B_{\max }$ or $K_{D}$ by a one-way ANOVA $(F[2,15]=0.245, p=$ $.79)$ and $(F[2,15]=0.134, p=.876)$, respectively.

Figure $1 \mathrm{~B}$ provides the comparison of $\left[{ }^{3} \mathrm{H}\right] \mathrm{GBR} 12935$ binding site density $\left(B_{\max }\right)$ in the prefrontal cortex following 1 week of withdrawal from either continuous cocaine administration via mini-pump, intermittent cocaine, or saline administration via daily injections. Significant group differences were detected for $B_{\max }$ by a one-way ANOVA $(F[2,15]=5.8, p=.014)$. A post hoc $t$-test comparison indicated no difference between the two cocaine treatment groups. When compared to the saline-injected control rats, the chronic infusion cocaine group was not different; however, in the chronic injection cocaine group $B_{\max }$ was reduced by $48 \%(t=3.4$, 
$p=.01)$. The affinity constants $\left(K_{D}\right)$ were not significantly different from the saline injected controls in either of the cocaine-treated groups $\left[K_{D} n M\right.$ mean(SD) saline $=10.8(4)$; injection $=7.2(6)$; infusion $=6.7(5)]$.

One week of withdrawal from continuous cocaine administration via mini-pump resulted in a significant increase in $\left[{ }^{3} \mathrm{H}\right]$ WIN 35,428 binding in the striatum. There was a $151 \%$ increase $(p<.001)$ in the density of $\left[{ }^{3} \mathrm{H}\right]$ WIN 35,428 binding in the dorsomedial aspect of the caudate and a 95\% increase $(p<.02)$ in the ventromedial aspect of the caudate nucleus, while the binding in the nucleus accumbens was not significantly changed. No binding of $\left[{ }^{3} \mathrm{H}\right]$ WIN 35,428 was detected in the prefrontal cortex in either group of animals. Figure 2 illustrates the increase in the density of $\left[{ }^{3} \mathrm{H}\right]$ WIN 35,428 binding in the dorsomedial aspects of the caudate nucleus in cocaine-treated rats relative to controls $(p<$ .005). The density of $\left[{ }^{3} \mathrm{H}\right]$ WIN 35,428 binding in the saline-treated controls was $0.56(0.06)$, and in the cocainetreated rats it was $1.41(0.23) \mathrm{nCi} / \mathrm{mg}$.

\section{DISCUSSION}

The intermittent injections of cocaine at withdrawal day 7 produced a decrease in the number of $\left[{ }^{3} \mathrm{H}\right] \mathrm{GBR} 12935$ binding sites, while the continuous infusion of cocaine had no effect on DAT binding in the prefrontal cortex. Cocaine had no effect on $\left[{ }^{3} \mathrm{H}\right] \mathrm{GBR} 12935$ binding sites in the caudate-putamen.

The effect of chronic cocaine infusion was selective to sites labeled by $\left[{ }^{3} \mathrm{H}\right]$ WIN 35,428 and not to $\left[{ }^{3} \mathrm{H}\right] \mathrm{GBR}$ 12935. Our present data support the view that the functional domains that bind $\left[{ }^{3} \mathrm{H}\right] \mathrm{WIN} 35,428$, cocaine, and its analogues may be different from the functional domains that bind $\left[{ }^{3} \mathrm{H}\right] \mathrm{GBR} 12935$. This view is supported by the following indications: (1) Although there

\section{$\left[{ }^{3} \mathrm{H}\right]$ WIN 35428}

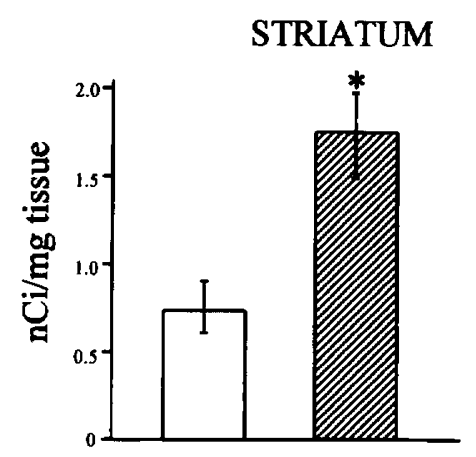

Figure 2. $\left[{ }^{3} \mathrm{H}\right]$ WIN 35,428 binding in the dorsomedial aspects of the caudate nucleus in cocaine-treated rats relative to controls. The density of $\left[{ }^{3} \mathrm{H}\right]$ WIN 35,428 binding in the saline treated controls was $0.56(0.06)$ and $1.41(0.23) \mathrm{nCi} / \mathrm{mg}$ in the cocaine-treated rats ( $\square$ saline, $\square$ cocaine infusion). is DAT-associated $\left[{ }^{3} \mathrm{H}\right] \mathrm{GBR} 12935$ binding in the frontal cortex (Hitri et al. 1991, 1994; Hitri and Wyatt 1993, 1994), DAT-associated binding of [ $\left.{ }^{3} \mathrm{H}\right]$ WIN 35,428 has not been detected in the frontal cortex (Canfield et al. 1990); (2) [ $\left.{ }^{3} \mathrm{H}\right]$ GBR 12935 binds in the striatum to a single site that is not fully displaceable with cocaine (Andersen 1987); (3) cocaine and its congeners are five to 10 times less potent in displacing $\left[{ }^{3} \mathrm{H}\right] \mathrm{GBR} 12935$ sites than $\left[{ }^{3} \mathrm{H}\right]$ cocaine sites in the striatum (Madras et al. 1989); (4) cocaine minimally inhibits $\left[{ }^{3} \mathrm{H}\right] \mathrm{GBR} 12935$ binding in the frontal cortex (Hitri et al. 1991); (5) GBR 12909 and mazindol fully inhibit neither $\left[{ }^{3} \mathrm{H}\right]$ cocaine nor $\left[{ }^{3} \mathrm{H}\right]$ WIN 35428 binding in the striatum (Canfield et al. 1990); (6) destruction of corticostriatal projections causes a selective increase in $\left[{ }^{3} \mathrm{H}\right]$ cocaine-labeled DATR without changing the binding sites for $\left[{ }^{3} \mathrm{H}\right] \mathrm{GBR} 12935$ (Grilli et al. 1988); (7) unlike the saturable $\left[{ }^{3} \mathrm{H}\right]$ WIN 35,428 binding to the cloned DAT in the COS-7 cells, $\left[{ }^{3} \mathrm{H}\right]$ GBR 12935 binding to the cloned DAT is not saturable and not displaceable by dopamine uptake blockers (Pristupa et al. 1994); (8) Comparison of the binding patterns of $\left[{ }^{3} \mathrm{H}\right]$ WIN 35,428 and $\left[{ }^{3} \mathrm{H}\right]$ GBR 12935 in the basal ganglia indicates different anatomical localization of the two ligand binding sites (Wilson et al. 1994). Taken together, these data suggest that the projections of dopaminergic neurons from the substantia nigra and ventral tegmental area may express different forms of DAT with different proportions of $\left[{ }^{3} \mathrm{H}\right] \mathrm{GBR} 12935$ and [ ${ }^{3} \mathrm{H}$ ]WIN 35,428 binding sites (Wilson et al. 1994). Moreover, the absence of saturable $\left[{ }^{3} \mathrm{H}\right] \mathrm{GBR} 12935$ binding to the cloned DAT in the transfected COS-7 is in contrast to the presence of saturable $\left[{ }^{3} \mathrm{H}\right] \mathrm{GBR} 12935$ binding to the native DAT in the human brain, indicating the existence of two distinct, but pharmacologically similar, DATs in vivo (Pristupa et al. 1994).

Unlimited chronic access to cocaine in cocaine selfadminstering rats is associated with increased $\left[{ }^{3} \mathrm{H}\right]$ WIN 35,428 binding in the striatum and nucleus accumbens in the early stages of withdrawal, whereas in the late stages of withdrawal the changes are different and the regional pattern of cocaine's effect is altered (Wilson et al. 1994). Three weeks after the last intake of cocaine [ $\left.{ }^{3} \mathrm{H}\right]$ WIN 35,428 binding was mainly normal in the striatum, but it was decreased $(30 \%)$ in the nucleus accumbens (Wilson et al. 1994). In contrast to [ $\left.{ }^{3} \mathrm{H}\right]$ WIN 35,428, the $\left[{ }^{3} \mathrm{H}\right]$ GBR 12935 -labeled DATR showed a smaller, highly subregionally dependent increase in binding in striatal subdivisions, on the last day of cocaine intake, and a larger binding reduction after 3 weeks of withdrawal (Wilson et al. 1994).

Using a different administration schedule, we detected regional differences in the delayed effects of cocaine on $\left[{ }^{3} \mathrm{H}\right]$ GBR 12935 -labeled DATR (Hitri and Wyatt 1993). While chronic intermittent injection of cocaine in rats was associated with a delayed and persistent decrease in DATR in the prefrontal cortex, it had no effect 
on DATR in the striatum (Hitri and Wyatt 1993). Consistently, daily injections of cocaine produced no change in striatal $\left[{ }^{3} \mathrm{H}\right]$ GBR $12935-D A T R$ binding, 3 to 14 days after withdrawal (Allard et al. 1990; Yi and Johnson 1990); moreover, repeated passive intermittent intravenous administration of cocaine had no effect on striatal $\left[{ }^{3} \mathrm{H}\right] \mathrm{GBR}$ 12935-DATR binding (Pilotte et al. 1994), and DATR labeled with $\left[{ }^{3} \mathrm{H}\right]$ mazindol was not altered either (Benmansour et al. 1992; Kula and Baldessarini 1991). In contrast, $\left[{ }^{3} \mathrm{H}\right]$ WIN 35,428 binding, while showing no change in the striatum, was significantly decreased in the nucleus accumbens of rats treated with cocaine and withdrawn for 10 to 60 days (Pilotte et al. 1994).

The increase in $\left[{ }^{3} \mathrm{H}\right]$ WIN 35,428 binding in the caudate- putamen is consistent with previous results (Little et al. 1993; Staley et al. 1993; Wilson et al. 1994), but not with the results of Pilotte et al. (1994), who found decreased [ ${ }^{3} \mathrm{H}$ ]WIN 35,428 binding in the nucleus accumbens. Differences in administration schedule (Pilotte et al. gave $10 \mathrm{mg} / \mathrm{kg} /$ day IV over 2 hours $\times 10$ days) and rat strain (Lewis) may account for the different findings. Both Wilson and Pilotte administered cocaine IV; however in the Wilson et al. (1994) study animals selfadministered more sustained daily doses of cocaine than in the Pilotte et al. (1994) study. Both the titration based on subjective effect, as well as the total cumulative dose may contribute to differences in binding results.

While the continous exposure to cocaine in our study did not produce alterations in GBR 12935 binding, the intermittent exposure to the same cumulative dose of cocaine resulted in reduction of the $B_{\max }$. During intermittent injections of cocaine perturbations are precipitated by the fluctuating cocaine levels. Neuronal perturbations caused by the administration and the clearance of cocaine involve cocaine-induced inhibition of DAT and prevention of normal reuptake removal of DA from the synapse. Consequent to DA receptor stimulation there is a feedback suppression of DA neuronal activity and a reduction of DA in the terminal field. The system is reset following the clearance of cocaine, and the cycle is repeated with the readministration of cocaine. It seems that the neuronal perturbations associated with the intermittent exposure to cocaine may be more important than the continuous presence of cocaine for the observed reduction in $\left[{ }^{3} \mathrm{H}\right] \mathrm{GBR}$ 12935-labeled DATR. Wyatt et al. (1988).

In this study the decrease in $\left[{ }^{3} \mathrm{H}\right] \mathrm{GBR} 12935$ binding in the prefrontal cortex of the injected rats appeared a week earlier than in our previous study (Hitri and Wyatt 1993). The difference is likely due to the variation in treatment duration.

In summary the data demonstrate a pattern of increased $\left[{ }^{3} \mathrm{H}\right]$ WIN 35,428 binding in the caudate putamen of rats with continuous infusion of cocaine on day 7 after withdrawal and are consistent with the human postmortem data in cocaine users (Little et al. 1993). The decreased $\left[{ }^{3} \mathrm{H}\right] \mathrm{GBR} 12935$ binding in the prefrontal cortex of rats, following intermittent injections of cocaine, is also consistent with the findings of human postmortem studies (Hitri et al. 1994b; Hurd and Herkenham 1993).

\section{ACKNOWLEDGMENTS}

The authors wish to thank Stephen I. Deutsch, M.D., Ph.D., for his valuable administrative help and support in carrying out part of this study in the NIDA/VA laboratories. This research was supported in part by NIDA grant 05303 (E. H. Ellinwood, Jr., principal investigator) and in part by the NIDA/VA interagency agreement No. RA-ND-90-10 (S. I. Deutsch, principal investigator).

\section{REFERENCES}

Allard P, Eriksson K, Ross SB, Marcusson JO (1990): Unaltered $\left[{ }^{3} \mathrm{H}\right]$ GBR 12935 binding after chronic cocaine treatment with dopamine active drugs. Psychopharmacology 102: 291-294

Andersen PH (1987): Biochemical and pharmacological characterization of $\left[{ }^{3} \mathrm{H}\right] \mathrm{GBR} 12935$ binding in vitro to rat striatal membranes: Labeling of the dopamine uptake complex. J Neurochem 48:1887-1896

Benmansour S, Tejani-Butt SM, Hauptman M, Brunswick DJ (1992): Lack of effect of high-dose cocaine on monoamine uptake sites in rat brain measured by quantitative autoradiography. Psychopharmacology 106:459-462

Broderick PA (1992): Distinguishing effects of cocaine IV and SC on mesoaccumbens dopamine and serotonin release with chloral hydrate anesthesia. Pharmacol Biochem Behav 43:929-937

Canfield DR, Spealman RD, Kaufman MJ, Madras BK (1990): Autoradiographic localization of cocaine binding sites by $\left[{ }^{3} \mathrm{H}\right] \mathrm{CFT}\left({ }^{3} \mathrm{H}\right]$ WIN 35,428$)$ in the monkey brain. Synapse 6:189-195

Cass WA, Gerhardt GA, Gillespie K, Curella P, Mayfield RD, Zahniser NR (1993): Reduced clearance of exogenous dopamine in rat nucleus accumbens, but not in dorsal striatum, following cocaine challenge in rats withdrawn from repeated cocaine administration. J Neurochem 61: 273-283

Falk JL, Fang M, Lau CE (1991): Chronic oral cocaine selfadministration: Pharmacokinetics and effects on spontaneous and discriminative motor functions. J Pharmacol Exp Ther 257:457-465

Freedman P (1991): GB-STAT Professional Statistics \& Graphics, Version 3.0. Silver Spring, MD, Dynamic Microsystems, Inc.

Gawin FH, Ellinwood EH (1988): Cocaine and other stimulants. New Eng1 J Med 318:1173-1182

Gawin FH, Kleber HD (1986): Abstinence symptomology and psychiatric diagnosis in cocaine abusers. Arch Gen Psychiatry 43:107-113

Grilli ME, Sanna E, Hanbauer I (1988): Role of corticostriatal nerve projections in the regulation of binding sites for 
dopamine uptake blockers in rat caudate nucleus. Soc Neurosci Abst 14:929

Hitri A, Wyatt RJ (1994): Questions about the dopaminergic nature of $\left[{ }^{3} \mathrm{H}\right] \mathrm{GBR} 12935$ binding in the human frontal cortex. J Neurochem 63:1181-1182

Hitri A, Wyatt RJ (1993): Regional differences in rat brain dopamine transporter binding: Function of time after chronic administration. Clin Neuropharmacol 16:526-539

Hitri A, Venable D, Nguyen HQ, Casanova MR, Kleinman JE, Wyatt RJ (1991): Characteristics of [ $\left.{ }^{3} \mathrm{H}\right] \mathrm{GBR} 12935$ binding in the human and rat frontal cortex. J Neurochem 56:1663-1672

Hitri A, Hurd YL, Wyatt RJ, Deutsch SI (1994a): Molecular functional and biochemical characteristics of the dopamine transporter: Regional differences and clinical relevance. Clin Neuropharmacol 17:1-22

Hitri A, Casanova MF, Kleinman JE, Wyatt RJ (1994b): Fewer dopamine transporter receptors in the prefrontal cortex of cocaine abusers. Am J Psychiatry 151:1074-1076

Hurd YL, Herkenham M (1993): Molecular alterations in the neostriatum of human cocaine addicts. Synapse $13: 357-369$

Izenwasser S, Cox BM (1990): Daily cocaine treatment produces a persistent reduction of $\left[{ }^{3} \mathrm{H}\right]$ dopamine uptake in vitro in the rat nucleus accumbens but not in the striatum. Brain Res 531:338-341

Johanson CE (1984): Assessment of the dependence potential of cocaine in animals. In Grabowski J (ed) Cocaine: Pharmacology, Effect and Treatment of Abuse. NIDA Research Monograph No. 50. Washington, DC, U.S. Government Printing Office, pp 72-91

Joyner C, King G, Lee TH, Ellinwood EH (1993) Technique for the continous infusion of high doses of cocaine by osmotic minipump. Pharmacol Biochem Behav 44:971-973

King GR, Joyner CM, Lee T, Kuhn C, Ellinwood EH (1992a): Intermittent and continuous cocaine administration: Residual behavioral states during withdrawal. Pharmacol Biochem Behav 43:243-248

King GR, Kuhn C, Ellinwood EH (1992b): Dopamine efflux during withdrawal from continuous or intermittent cocaine. Psychopharmacology 111:179-184

King GR, Joyner CM, Lee T, Ellinwood EH (1993): Withdrawal from continuous or intermittent cocaine: Effect of NAN-90 on cocaine induced locomotion. Pharmacol Biochem Behav 44:253-262

Konig JFR, Klippel RA (1963): The Rat Brain: A Stereotaxic Atlas of the Forebrain and Lower Parts of the Brain Stem. Baltimore, Williams and Wilkins

Kula NS, Baldessarini RJ (1991): Lack of increase in dopamine transporter binding or function in rat brain tissue after treatment with blockers of neuronal uptake of dopamine. Neuropharmacology 30:89-92

Lau CE, Imam A, Fang M, Falk JL (1991): Acute effects of cocaine on spontaneous and discriminative motor functions: Relation to route of administration and pharmakinetics. J Pharmacol Exp Ther 257:444-456

Little KY, Kirkman JA, Carroll FI, Clark TB, Duncan GE (1993): Cocaine use increases [ ${ }^{3} \mathrm{H}$ ]WIN 35,428 binding sites in human striatum. Brain Res 628:117-125
Madras BK, Spealman RD, Fahey MA, Neumeyer JL, Saha JK, Milius RA (1989): Cocaine receptors labeled by [ $\left.{ }^{3} \mathrm{H}\right] 2 \mathrm{~B}-$ Carbomethoxy-3B-(4-fluorophenyl)tropane. Mol Pharmacol 36:518-524

McPherson GA (1985): Analysis of the radioligand binding experiments: A collection of computer programs for the IBM PC. J Pharmacol Methods 14:213-228

Pilotte NS, Sharpe LG, Kuhar MJ (1994): Withdrawal of repeated intravenous infusion of cocaine persistently reduces binding to dopamine transporters in the nucleus accumbens of Lewis rats. J Pharmacol Exp Ther 269:963-969

Post RM, Contel NR (1983): Human and animal studies of cocaine: Implications for development of behavioral pathology. In Creese I (ed), Stimulants: Neurochemical, Behavioral and Clinical Perspective, New York, Raven, pp 169-203

Post RM, Lockfeld A, Squillace KM, Contel NR (1981): Drug environment interaction: Context dependency of cocaine induced behavioral sensitization. Life Sci 28:755-760

Pristupa ZB, Wilson JM, Hoffman BJ, Kish SJ, Niznik HB (1994): Pharmacological heterogeneity of the cloned and native human dopamine transporter: Disassociation of $\left[{ }^{3} \mathrm{H}\right]$ WIN 35,428 and $\left[{ }^{3} \mathrm{H}\right] \mathrm{GBR} 12935$ binding. Mol Pharmacol 45:125-135

Reith MEA, Benuck M, Lajtha A (1987): Cocaine disposition in the brain after continuous or intermittent treatment and locomotor stimulation in mice. J Pharmacol Exp Ther 243:281-287

Ritz MC, Lamb RJ, Goldberg SR, Kuhar MJ (1987): Cocaine receptors on dopamine transporters are related to selfadministration of cocaine. Science 23:1219-1223

Staley J, Flynn DD, Stitt F, Wetli CV, Mash DC (1993): $\left[{ }^{3} \mathrm{H}\right]$ WIN 35,428 binding to the dopamine transporter in cocaine overdose deaths. Abst Soc Neurosci 19:1843

Stripling JS, Ellinwood EH, Jr. (1976): Cocaine: Physiological and behavioral effects of acute and chronic administration. In Mule SJ (ed), Cocaine: Chemical, Biological Clinical, Social and Treatment Aspects, Cleveland, $\mathrm{OH}, \mathrm{CRC}$ Press, pp 167-185

Wilson JM, Nobrega JN, Carroll ME, Niznik HB, Shannak K, Lac ST, Pristupa ZB, Dixon LM, Kish SJ (1994): Heterogeneous subregional binding patterns of $\left[{ }^{3} \mathrm{H}\right] \mathrm{WIN}$ 35,428 and [ ${ }^{3} \mathrm{H}$ ]GBR 12935 are differently regulated by chronic cocaine self-administration. J Neuroscience 14: 2868-2979

Wyatt RJ, Karoum F, Suddath R, Hitri A (1988): The role of dopamine in cocaine use and abuse. Psychiatric Ann 18:531-534

Yi SJ, Johnson KM (1990): Effects of acute and chronic administration of cocaine on striatal uptake, compartmentalization and release of $\left[{ }^{3} \mathrm{H}\right]$ dopamine. Neuropharmacology 29:475-486

Zhang H, Lee TH, Ellinwood EH (1992): The progressive changes of neuronal activities of the nigral dopaminergic neurons upon withdrawal from continuous infusion of cocaine. Brain Res 594:315-318 